\title{
Tensile mechanical properties, constitutive parameters and fracture characteristics of an as-cast AA7050 alloy in the near-solidus temperature regime
}

T. Subroto ${ }^{1,2}$, A. Miroux ${ }^{1,2}$, D. G. Eskin ${ }^{3,4, *}$ and L. Katgerman ${ }^{2}$

1) Materials innovation institute (M2i), Elektronicaweg 25, 2628XG Delft, The Netherlands

2) Department of Materials Science and Engineering, Delft University of Technology, Mekelweg 2, Delft, 2628CD, The Netherlands

3) Brunel University London, BCAST, Uxbridge, Middlesex, UB8 3PH, United Kingdom

4) Tomsk State University, Tomsk, 634050 Russia

*) Corresponding author (e-mail: dmitry.eskin@brunel.ac.uk)

\begin{abstract}
The knowledge on constitutive mechanical behavior at the temperatures close to the solidus is essential for predicting high-temperature deformation and fracture, e.g. cold and hot cracking of aluminum alloys. In this work we studied the tensile mechanical properties of an as-cast AA7050 alloy in a near-solidus temperature regime. Tensile tests were carried out using Gleeble-3800 ${ }^{\mathrm{TM}}$ system at temperatures from 400 to $465^{\circ} \mathrm{C}$ and at strain rates from 0.0005 to $0.05 \mathrm{~s}^{-1}$. The results show that the strength decreases with increasing temperature and decreasing strain rate. Meanwhile, ductility decreases with the increase of temperature and strain rate. The constitutive parameters were extracted by fitting the test data to the extended-Ludwik and creep-law equations. The parameters for the extended-Ludwik equation are continuous with the values from a lower temperature regime obtained earlier, while the parameters for the creep-law equation are comparable with those obtained on other 7XXX aluminum alloys. We observed a change in fracture mode at $450{ }^{\circ} \mathrm{C}$; from ductile transgranular to intergranular. This temperature coincides with the discontinuity point of the temperature-ductility slope. On the fracture surface of a sample that was deformed at $465^{\circ} \mathrm{C}$ with a strain rate of $0.0005 \mathrm{~s}^{-1}$, we observed features characteristic of micro-superplasticity. Considering the test conditions, viscous flows of incipient melt or liquid-like substances are suggested to be responsible for the formation of this feature.
\end{abstract}


Keywords: AA7050, near-solidus temperature, tensile mechanical behavior, constitutive parameters, fracture surface analysis.

\section{Introduction}

High strength aluminum alloy from 7XXX family such as AA7050 is considered interesting for industries that require light weight and strong materials such as aviation industries. This is because AA7050 possess good strength-to-weight ratio, considerable fracture toughness and good stress corrosion cracking resistance [1, 2]. Despite its positive characteristics, the main bottleneck for this alloy is its behavior during its production stage, such as during ingot casting. This is because AA7050 is known to be susceptible to cracking during casting and immediately after casting. In order to obtain the best production output and minimize casting failure, it is important to possess the knowledge of constitutive behavior and fracture characteristics of this alloy in different temperature ranges. Constitutive parameters of the alloy which are extracted from mechanical properties of the alloy through, for instance, tensile tests at different temperatures and strain rates are important as an input for numerical process simulation of different production processes, i.e. casting [3, 4] and hot forming [5].

The result from such a process simulation strongly depends on the quality of the material properties dataset that is used as the input of the simulation [6, 7]. As indicated by Lalpoor et al. [8], although the properties of materials in its as-cast state are critical for the quality of simulation output, the data is not easily accessible in literature and often the available data are either from processed or heat-treated metals. Although Lalpoor et al. [8] studied tensile constitutive behavior of AA7050 in its as-cast state starting from room temperature up to $400^{\circ} \mathrm{C}$; they did not analyzed in detail the temperature range around the nonequilibrium solidus point $465{ }^{\circ} \mathrm{C}$ for AA7050. The temperatures around nonequilibrium solidus point are considered quite important both from scientific and technological point of view, because around this temperature point crucial phenomena, e.g. incipient melting could occur. From mechanical properties standpoint, this temperature range is also quite essential because this is the regime where strength and ductility of the alloy drop significantly [3, 9, 10]. This information is potentially critical for optimizing the production output. Despite its importance, only limited amount of as- 
cast data are available in the reference sources and most of them are for alloys that have been homogenized $[11,12]$ or pre-processed (for instance, as-rolled alloys) [13, 14]. These data could not be used as representative of as-cast condition, as the mechanical properties are quite different [8].

The main goal of this work is to acquire tensile mechanical behavior of AA7050 in its as-cast condition around the nonequilibrium solidus, and analyze its mechanical properties and fracture characteristics. To better understand the constitutive behavior and extract the constitutive parameters of the alloy, the acquired stress-strain curves at various temperatures and strain rates are fit to constitutive equations that are commonly used to analyze high temperature materials behavior, such as creep law [5] and extended-Ludwik equation [15]. Scanning electron microscopy (SEM) is employed to perform microstructural fracture surface analysis in order to gain insight of the fracture characteristics of the failed samples at various temperatures and strain rates.

\section{Experimental procedure}

The AA7050 alloy used in this experiment was produced using direct-chill (DC) casting method and supplied by Tata Steel Nederland Technology B.V. (IJmuiden). The melt was degassed in the furnace and a conventional bore mold was utilized during DC casting. Optical spectrum analysis was used to determine the chemical composition of the billet (see Table 1).

Table 1 Result of optical spectrum analysis for chemical composition of the AA7050 alloy used in this work.

\begin{tabular}{llllllllll}
\hline \multicolumn{10}{c}{ Alloying Elements, wt pct } \\
\hline $\mathrm{Zn}$ & $\mathrm{Mg}$ & $\mathrm{Cu}$ & $\mathrm{Zr}$ & $\mathrm{Fe}$ & $\mathrm{Mn}$ & $\mathrm{Si}$ & $\mathrm{Ti}$ & $\mathrm{Cr}$ & $\mathrm{Al}$ \\
\hline 6.3 & 2.42 & 2.49 & 0.098 & 0.07 & 0.04 & 0.04 & 0.03 & $<0.01$ & balance \\
\hline
\end{tabular}

In this work the tensile mechanical properties of the alloy at different temperatures and strain rates were obtained using a themo-mechanical simulator (Gleeble-3800 ${ }^{\mathrm{TM}}$, Dynamic System Inc.). Tensile samples were produced by machining parts from the as-cast billet. The geometry of tensile samples was made to be similar with the ones from the work performed in the lower temperature range [8] in order to have a comparable and continuous result. 
Resistive-heating was used to heat up the samples from room temperature to $400{ }^{\circ} \mathrm{C}$ using $5^{\circ} \mathrm{C} / \mathrm{s}$ heating rate. This followed by heating rate of $1^{\circ} \mathrm{C} / \mathrm{min}$ to the temperatures where mechanical tests were performed (i.e. 400, 420, 440, 450, 455, 460 and $465^{\circ} \mathrm{C}$ ). To control the test temperature, in the center of the samples a thermocouple was spot welded. A holding period of 40 seconds was performed in order to stabilize the temperature distribution. Subsequently the samples were tensile deformed until failed. Diametrical dilatometer was utilized to measure strain at all time during tests [10].

Three different strain rates, namely 0.0005, 0.005 and $0.05 \mathrm{~s}^{-1}$ were used to observe strain-rate sensitivity of the alloy at each temperature point. The tensile test was done at a constant displacement rate. The indicated strain rates are the initial strain rates of the tests, but for simplicity, henceforth it will be called as 'strain rate'. Such test parameters were selected because it is within the strain-rate range of DC casting process [16]. The test was repeated three times for each combination of temperature and strain rate to study the statistical behavior of the alloy. The standard deviation was used to plot the error bar in all figures. A Jeol JSM-6500F SEM was utilized to analyze the microscopic fracture surface of the tested samples.

\section{Results}

\subsection{Tensile mechanical behavior}

Figure 1 shows the true stress-strain curves obtained at different test temperatures with a strain rate of $0.05 \mathrm{~s}^{-1}$. The shape of the curves and the trends are representative of the observations at other strain rates. This figure shows that the strength of the alloy decreases as temperature increases. Moreover, the alloy becomes less ductile as the temperature increases. General shape of the stress-strain curves exhibits both hardening and flow stress behavior; the curves reach a peak value and then decrease to a steady-state stress value before the alloy subsequently fails (shown by the steep drop in strength). The length of the steady-state flow stage also decreases with increasing temperature as also shown in Figure 1. 


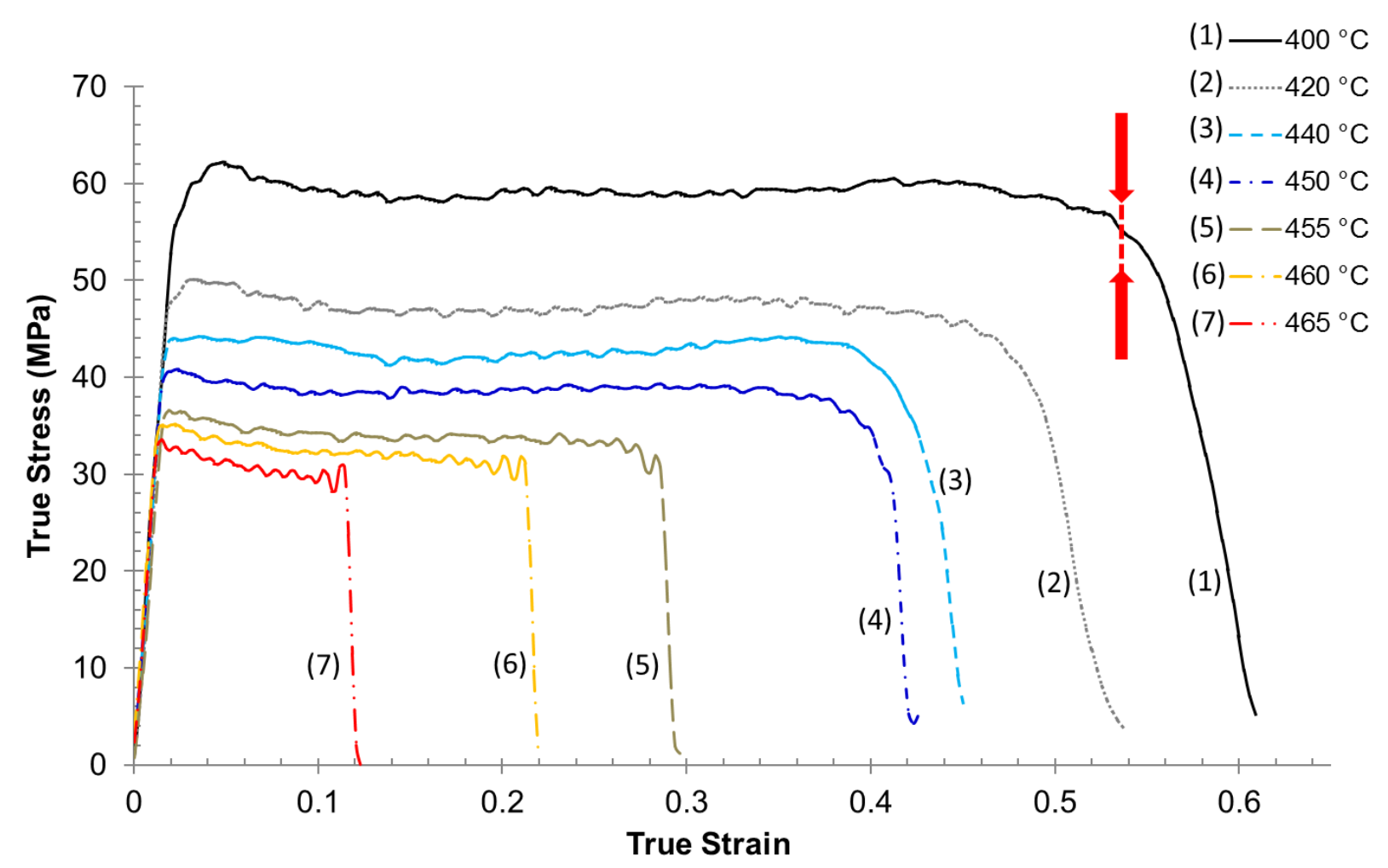

Figure 1 Tensile stress-strain curves at different temperatures from 400 to $465^{\circ} \mathrm{C}$ obtained at a strain rate of $0.05 \mathrm{~s}^{-1}$. An example of fracture true strain is shown by the red dashed line pointed by the arrows on the stress-strain curve obtained at $400{ }^{\circ} \mathrm{C}(1)$.

Examples of stress-strain curves for samples tested at $400{ }^{\circ} \mathrm{C}$ with different strain rates $(0.0005$, 0.005 and $0.05 \mathrm{~s}^{-1}$ ) are depicted in Figure 2. Generally the results from this temperature range have a stark contrast compared to the behavior of the alloy below $200^{\circ} \mathrm{C}$ [8]. One can see that the behavior of the alloy in this experimental temperature range after reaching steady state is rather ductile compared to the behavior below $200{ }^{\circ} \mathrm{C}$ which is brittle as reported elsewhere [8]. From Figure 2 it seems that the results from three repetitive tests on each strain rate are quite reproducible.

Figure 1 and Figure 2 show that the steady-state flow stress (SSFS) is quite evident in the obtained stress-strain curves. We use SSFS value to represent the strength of the alloy in this work. The average of stress value in the steady-state stress deformation region (after the peak stress point was passed) is used to determine SSFS. The average of SSFS from three repeated 
tests was used to represent SSFS value for each combination of temperature and strain-rate. Thick dashed grey line shown in Figure 2 is an example of SSFS for a test performed at $400{ }^{\circ} \mathrm{C}$ with a strain rate of $0.005 \mathrm{~s}^{-1}$.

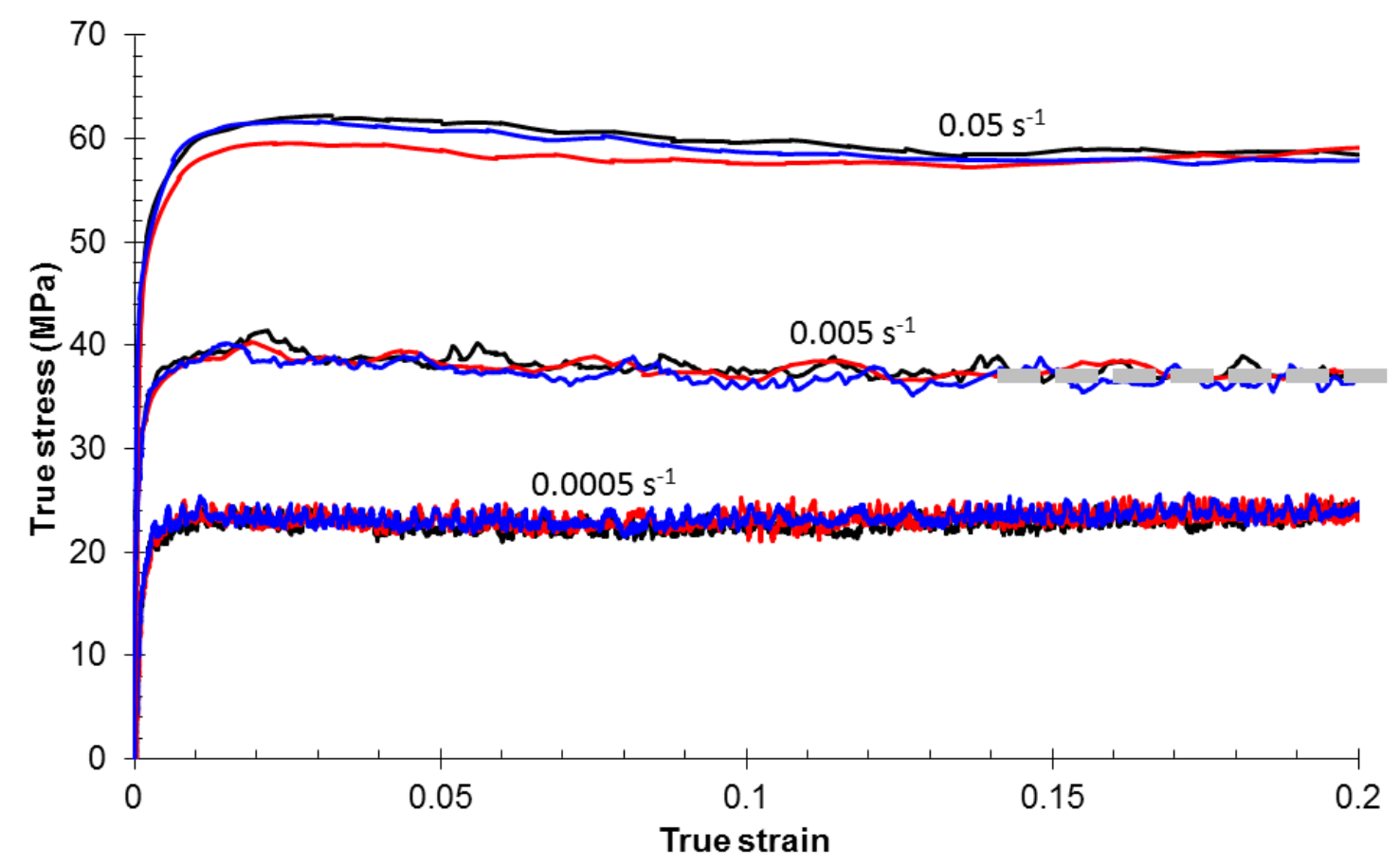

Figure 2 Tensile stress-strain curves tested at $400{ }^{\circ} \mathrm{C}$ with different strain rates. An example of steady-state flow stress (SSFS) is illustrated by a thick dashed grey line at a strain rate of 0.005 $\mathrm{s}^{-1}[10]$.

As shown in Figure 3, the strength of the alloy (measured through SSFS) decreases with decreasing strain-rate and increasing temperature. Each data point is an average of SSFS from three repeated tests. Figure 3 also gives the error bars for each data point but the span of the error bars is often comparable with the size of the symbol. From the same figure, we observed that the most substantial SSFS decrease occurs between 400 and $420^{\circ} \mathrm{C}$ as compared to the decrease beyond $420^{\circ} \mathrm{C}$. This phenomenon is quite surprising because this temperature range is well below the nonequilibrium solidus $\left(465^{\circ} \mathrm{C}\right.$ for AA7050) [10]. 


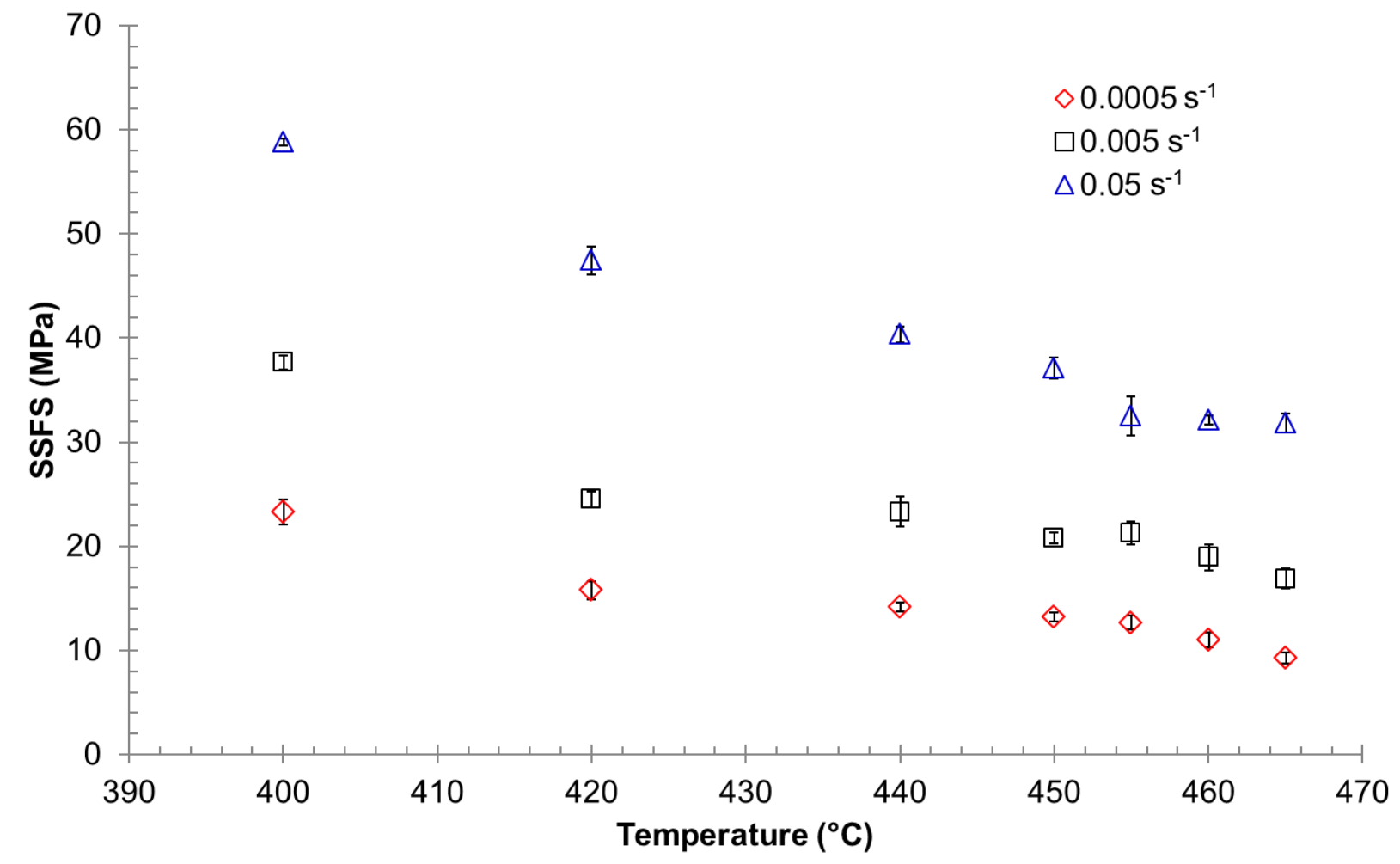

Figure 3 Steady-state flow stress (SSFS) at different test temperatures and strain rates [10].

Figure 4 shows that in this temperature range, fracture strain (defined as the strain value at the beginning of the sharp drop in stress value after it has passed the steady-state deformation range) decreases as temperature and strain rate increase despite the possibility of SSFS measurement, which implies the alloy is still relatively ductile. The steepness of slope between fracture-strain and temperature change quite significantly at $450{ }^{\circ} \mathrm{C}$; the slope is steeper above $450{ }^{\circ} \mathrm{C}$ and shallower below that temperature [10]. 


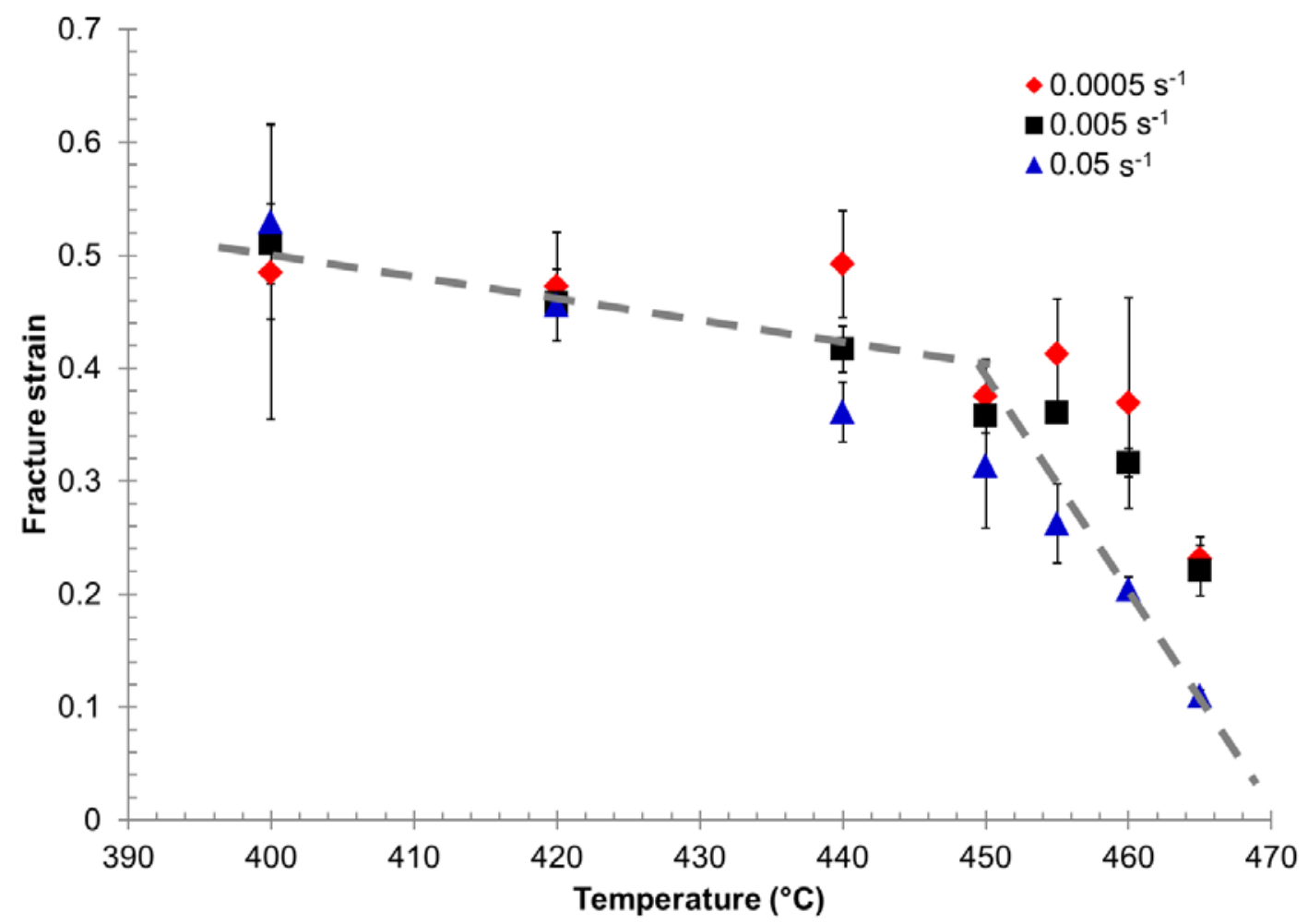

Figure 4 The relationship between fracture strain and temperature at different strain rates. The dashed grey lines show the trend in fracture strain with respect to temperature. The change in slope occurs at approximately $450{ }^{\circ} \mathrm{C}[10]$.

Figure 5 gives the hardening amount with respect to temperatures and strain rates. The hardening amount is defined here as the amount of strain from the end of the proportionality limit to the maximum stress on the stress-strain curve. This figure shows that the hardening decreases as temperature increases, and it reaches a saturation value of approximately 0.0075 starting from $450^{\circ} \mathrm{C}$. 


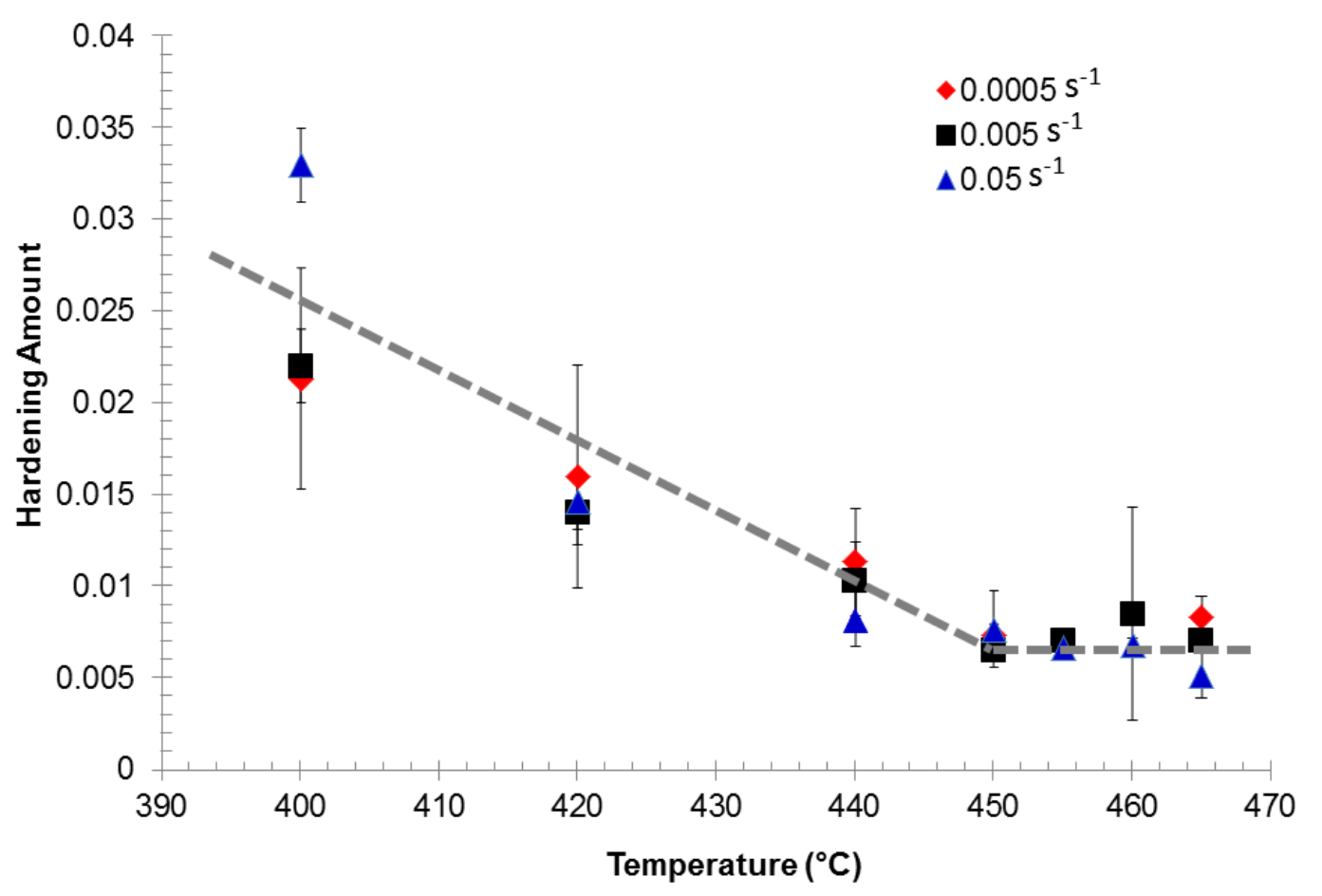

Figure 5 Hardening amount (strain from the proportionality limit up to the peak stress) in strain units vs. temperature at different strain rates. The grey dashed line shows the trend discontinuity in hardening at around $450{ }^{\circ} \mathrm{C}$.

\subsection{Fracture surface analysis}

Figure 6 shows fracture surface SEM images of samples tested at $400{ }^{\circ} \mathrm{C}$ at different strain rates. At $400{ }^{\circ} \mathrm{C}$ and the lowest strain rate $-0.0005 \mathrm{~s}^{-1}$ (Figure 6a and Figure 6b), the failure mode is generally mixed between intergranular and ductile transgranular, with the latter fracture type dominating. This is testified by the sharp features at the separation sites (last connection point before failure occurs) and dimples. Such features are also observed at the highest strain rate $0.05 \mathrm{~s}^{-1}$ (Figure 6c and Figure 6d) and we do not see many principal differences between these two strain rates. At a higher magnification, however, at the lowest strain rate, we observe broken eutectic phases with fine striation lines (red arrows in Figure 6b and Figure 6e). While at the highest strain rate, dimples (hole-like features) are the dominant features, while the striation lines are replaced with step-like features. 

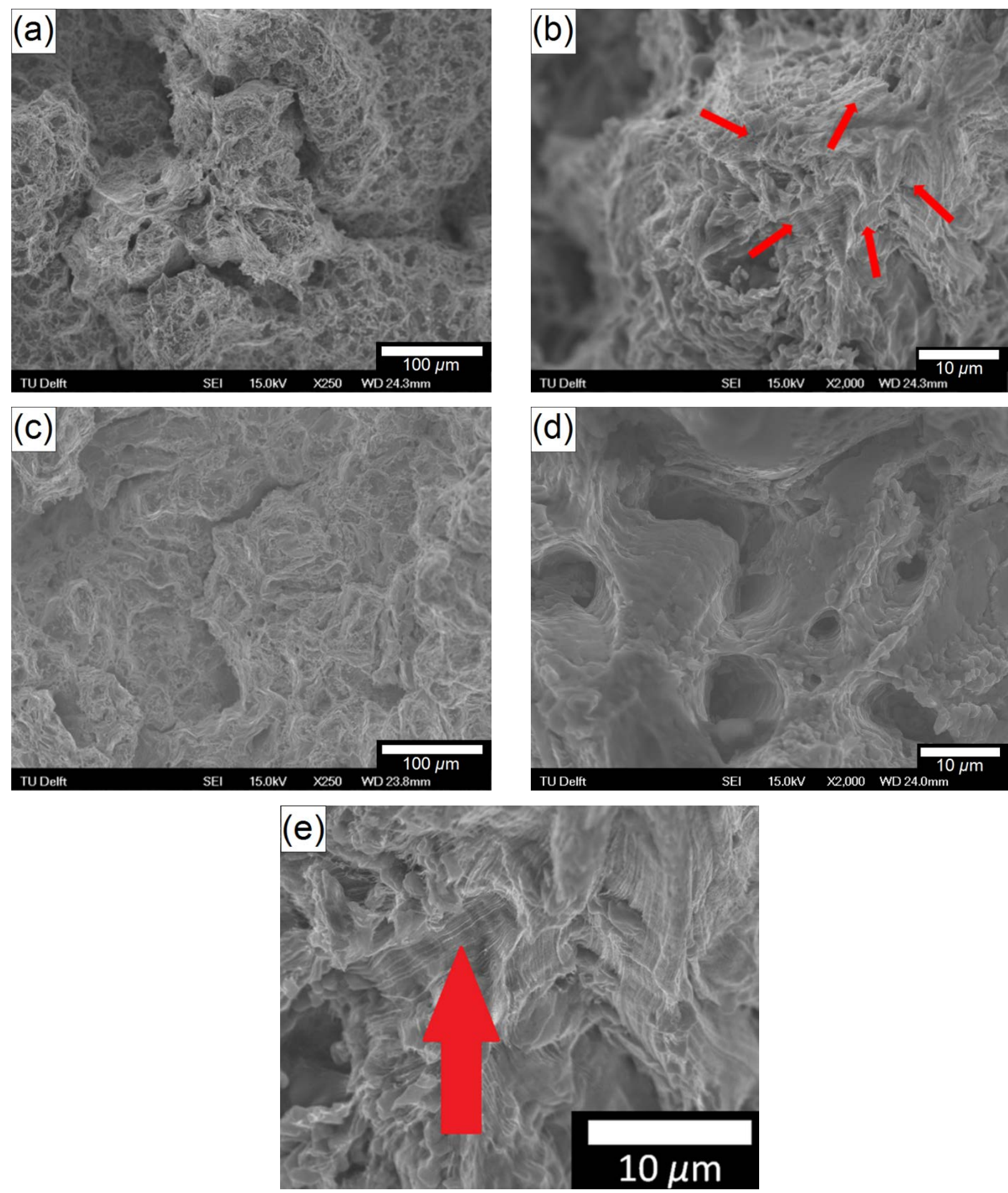

Figure 6 Example of fracture surfaces of samples tested at $400{ }^{\circ} \mathrm{C}$ : at the lowest strain-rate $\left(0.0005 \mathrm{~s}^{-1}\right)$, at low magnification (a) and high magnification (b) and at the highest strain-rate $\left(0.05 \mathrm{~s}^{-1}\right)$, at low magnification (c) and high magnification (d). An example of the striation lines (pointed by the red arrow) on the microstructure at high magnification (e). 

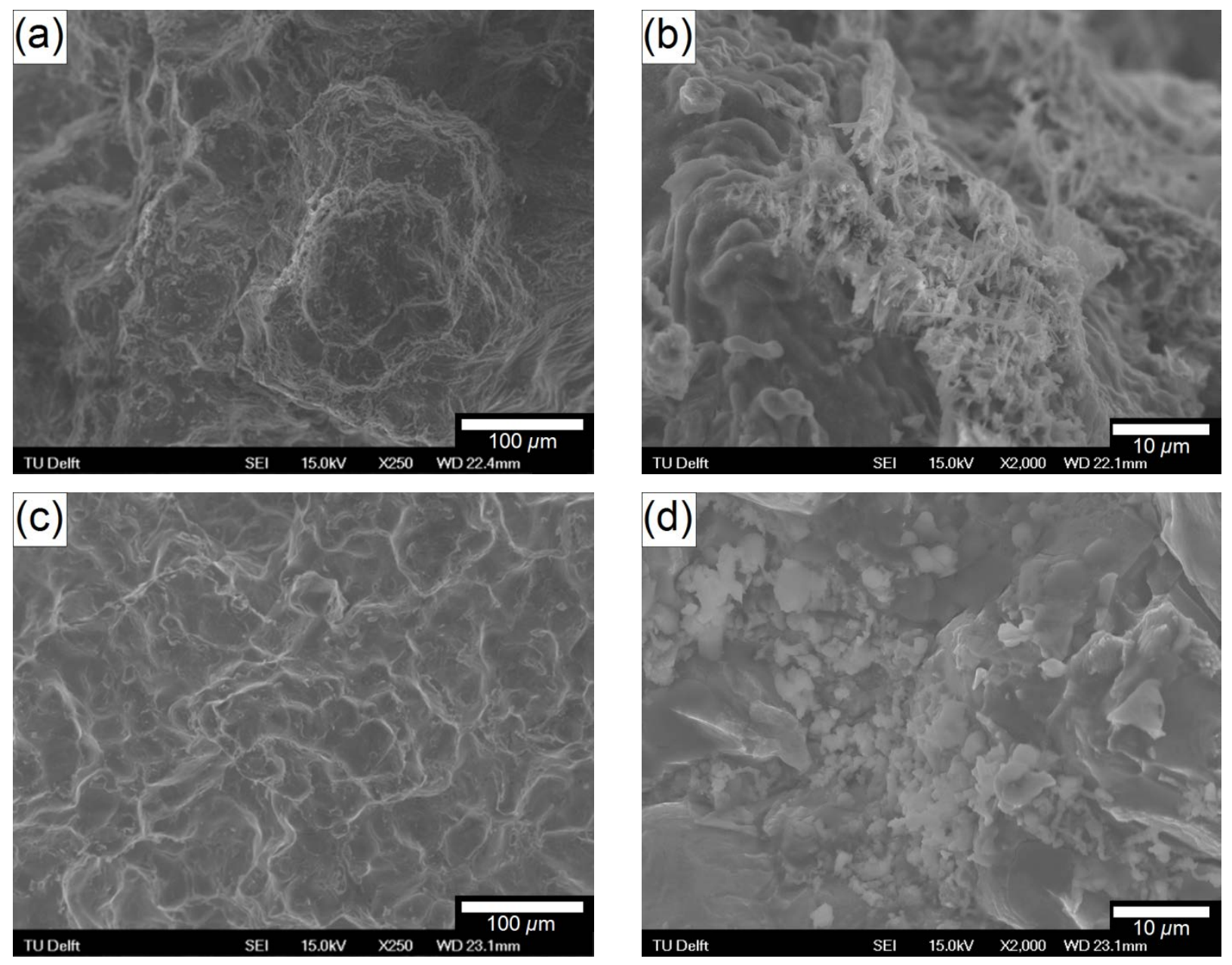

Figure 7 Example of fracture surface images of samples tested at $465^{\circ} \mathrm{C}$ : at the lowest strain-rate $\left(0.0005 \mathrm{~s}^{-1}\right)$, at low magnification (a) and high magnification (b) and at the highest strain-rate $\left(0.05 \mathrm{~s}^{-1}\right)$, at low magnification (c) and high magnification (d).

Figure 7 shows the fracture surfaces after tensile testing at $465{ }^{\circ} \mathrm{C}$ with different strain rates. Irrespective of strain rates, the main fracture mode is intergranular. The most significant difference between the two strain rates at $465{ }^{\circ} \mathrm{C}$ is the morphology of the eutectics (brighter phases in the pictures in Figure 7b and Figure 7d). Figure 7b shows elongated eutectics phases (filaments) at the lowest strain rate, while more rounded eutectic phases are evident in the fracture at the highest strain rate (Figure 7d). 
Figure 8a shows that at $440{ }^{\circ} \mathrm{C}$, although intergranular fracture mode starts to be visible, ductile transgranular sites is still the most frequent type (with sharp edges observed at the separation points - red ellipses in Figure 8). At $455^{\circ} \mathrm{C}$ however, the fracture mode becomes predominantly intergranular. This signifies that the change of dominant fracture mode occurs between these two temperature points.
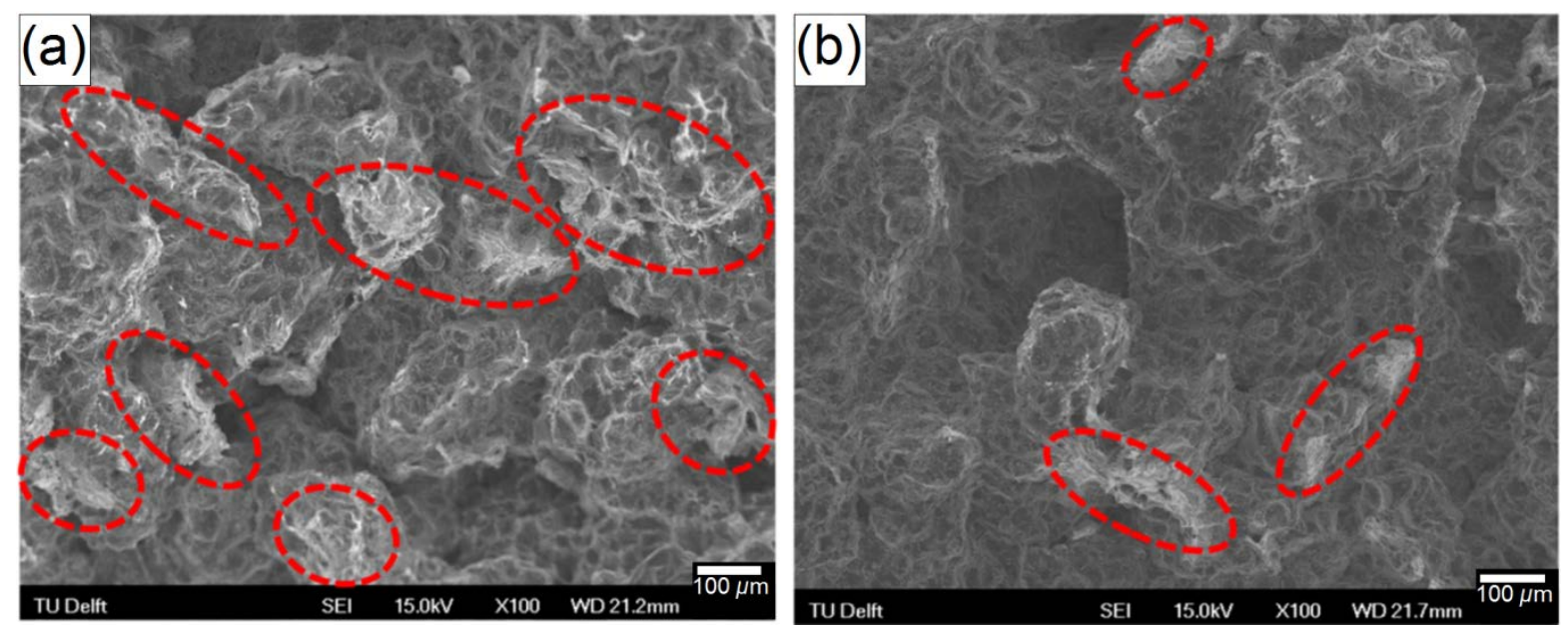

Figure 8 Fracture surface of tensile tested samples at a strain rate of $0.0005 \mathrm{~s}^{-1}$, at temperatures of $440{ }^{\circ} \mathrm{C}$ (a) and $455^{\circ} \mathrm{C}$ (b). Ductile transgranular features are areas within red ellipses.

\subsection{Constitutive parameters extraction}

Figure 1 shows that the stress-strain curves in the studied temperature range exhibit both mechanical features; hardening and steady-state flow. To obtain constitutive parameters from each behavior, we fit the tensile stress-strain curves to two different constitutive equations that represent different phenomena. The extended Ludwik equation is used as a representative of hardening behavior (eq. 1), which is as follows [15, 17]:

$$
\sigma=K(T)\left(\varepsilon_{\mathrm{p}}+\varepsilon_{\mathrm{p}}^{0}\right)^{r(T)}\left(\dot{\varepsilon_{\mathrm{p}}}\right)^{m(T)},
$$

where $K(T)$ is the consistency of the alloy (at $\varepsilon=1, \dot{\varepsilon}=1 \mathrm{~s}^{-1}$ ), $r(T)$ is the hardening parameter and $m(T)$ is the strain-rate sensitivity of the alloy. These parameters are temperature dependent. $\varepsilon_{\mathrm{p}}^{0}$ is a constant equal to $0.001[15,18]$. Meanwhile, the creep-law equation is used to represent the steady-state flow behavior (eq. 2), written as follows [19]: 


$$
\sigma=\sigma_{0} \exp \left(\frac{Q}{n R T}\right)\left(\frac{\dot{\varepsilon}_{\mathrm{s}}^{\mathrm{p}}}{\overline{\varepsilon_{0}}}\right)^{1 / n},
$$

where $Q$ is the activation energy, $n$ is the stress exponent, $R$ is the gas constant, $\dot{\varepsilon}_{\mathrm{s}}^{\mathrm{p}}$ is the plastic strain rate, $T$ is temperature, while both $\sigma_{0}$ and $\dot{\varepsilon}_{0}$ are materials constants.

Figure 1 shows some hardening in the temperature range from $400{ }^{\circ} \mathrm{C}$ to $450{ }^{\circ} \mathrm{C}$. Therefore, in this range we can fit the hardening part of the stress-strain curves (from the proportionality limit up to the maximum stress at the end of hardening) using the extended Ludwik equation (eq. 1). The fitting result based on this study is shown in Table 2, along with the fitting values for lower temperatures that are given from reference [15]. In this work, the constitutive parameters were extracted using an in-house built MATLAB routine. The precision is the confidence interval with a confidence level of $95 \%$.

Table 2 Constitutive parameters from extended-Ludwik fitting (eq. 1).

\begin{tabular}{cccc}
\hline Temperature $\left({ }^{\circ} \mathrm{C}\right)$ & $r$ & $m$ & $K$ \\
\hline $20[15]$ & $0.42 \pm 0.02$ & $-0.2 \pm 0.02$ & $774 \pm 32$ \\
$100[15]$ & $0.38 \pm 0.01$ & $-0.16 \pm 0.03$ & $626 \pm 13$ \\
$200[15]$ & $0.21 \pm 0.006$ & $-0.03 \pm 0.005$ & $392 \pm 11$ \\
$300[15]$ & $0.11 \pm 0.007$ & $0.03 \pm 0.007$ & $199 \pm 4.5$ \\
400 & $0.12 \pm 0.02$ & $0.16 \pm 0.06$ & $146 \pm 51$ \\
420 & $0.12 \pm 0.04$ & $0.17 \pm 0.10$ & $120 \pm 70$ \\
440 & $0.10 \pm 0.04$ & $0.14 \pm 0.06$ & $88 \pm 31$ \\
450 & $0.10 \pm 0.03$ & $0.15 \pm 0.08$ & $84 \pm 36$ \\
\hline
\end{tabular}

It is evident that above $300^{\circ} \mathrm{C}$ both hardening $(r)$ and strain-rate sensitivity parameter $(m)$ do not vary much with temperature. However, the consistency of the alloy $(K)$ decreases as temperature rises, which continues the trend from the lower temperature regime. Below $300{ }^{\circ} \mathrm{C}$, both $r$ and $\mathrm{K}$ decrease as temperature increases, while $m$ increases with temperature.

As the hardening behavior is active up to $450{ }^{\circ} \mathrm{C}$, steady-state flow stress becomes the only significant feature as the temperature approaches the nonequilibrium solidus (Figure 1). Thus, a creep law (eq. 2) is appropriate to fit the data in this temperature regime. From fitting SSFS versus temperature and strain rate, we obtained the creep-law parameters in (eq. 2) as follows: $\sigma_{0}$ $=0.01 \mathrm{MPa}, \dot{\varepsilon}_{0}=3.2210^{-4} \mathrm{~s}^{-1}, Q=185 \mathrm{~kJ} / \mathrm{mol}$ and $n=4.39$. 


\section{Discussion}

\subsection{Deformation mechanisms and fracture behavior}

Figure 2, Figure 3 and Table 2 show that the as-cast AA7050 alloy has positive strain-rate sensitivity as it approaches nonequilibrium solidus point. This trend is also supported by other works where similar AA7050 alloys have been studied but with different processing history [13, 14] and also for other families of aluminum alloys [5, 9, 20, 21]. The strain-rate sensitivity trend is relatively continuous over the entire temperature range studied here and in Refs. [3, 15].

In this test regime, the ratio $(\delta$ ) of SSFS value (shown in Figure 3; between 9.2 and $57 \mathrm{MPa}$ ) to the shear modulus of AA7050 (26.9 GPa) [22] is between $3.5 \times 10^{-4}$ (at $465^{\circ} \mathrm{C}$ and strain rate of $0.0005 \mathrm{~s}^{-1}$ ) and $2.1 \times 10^{-3}$ (at $400^{\circ} \mathrm{C}$ and strain rate of $0.05 \mathrm{~s}^{-1}$ ). It has been suggested [23] that dislocation creep becomes the dominant deformation mechanism close to the solidus $\left(10^{-4} \leq \delta \leq\right.$ $10^{-3}$ ); at $\delta>10^{-3}$ the main deformation mechanism is dynamic-recrystallization (DRX), and diffusion (Nabarro-Herring) creep is dominant at $\delta<10^{-4}$. The results from our tests show that the lowest SSFS value $\left(\delta=3.5 \times 10^{-4}\right)$ approaches diffusion creep regime boundary, while the highest SSFS value $\left(\delta=2.1 \times 10^{-3}\right)$ is within dynamic-recrystallization regime boundary. This may explain why the shape of stress-strain curves of samples deformed at $0.05 \mathrm{~s}^{-1}$ (Figure 1) resembles DRX occurrence - the stress reaches the peak followed by slight reduction and then goes to steady-state. It is also well known that grain boundary sliding (GBS) is one of the main deformation mechanisms at this temperature and low strain-rate regime [24].

The general shape of the stress-strain curves shown in Figure 1 corresponds to ductile behavior, which is common at high temperatures $[5,13,14]$. However, in this temperature regime, we found that the ductility decreases as the temperature increases (Figure 4). Although this behavior is rather counterintuitive [24], such a phenomenon has been observed in previous works on different types of metallic materials, such as copper [25], steels [26, 27] and other aluminum alloys $[8,9,26]$. We suggest that as the test temperature increases (and approaches the nonequilibrium solidus), diffusion creep becomes more dominant. This mechanism accelerates vacancy diffusion on the grain boundaries, and due to the imposed tensile stress, vacancy condensation occurs thus leading to void formation on grain boundaries [23, 28]. As the 
deformation continues, those voids subsequently coalesce on grain boundary facets and eventually lead to earlier failure [23, 29]. This is supported by SEM observations in Figure 7 and Figure 8b; as test temperature approaches the nonequilibrium solidus (above $450{ }^{\circ} \mathrm{C}$ ) fracture surface become mostly intergranular.

The temperature-ductility plot (Figure 4) shows a slope discontinuity at approximately $450{ }^{\circ} \mathrm{C}$ ( $T_{\text {switch }}$ ), i.e. a shallower ductility slope is observed below $T_{\text {switch }}$ while a steeper slope - above this point. From the fracture surface analysis, it appears that $\mathrm{T}_{\text {switch }}$ is also the point where the failure mechanism changed; below it is mostly ductile transgranular fracture, above it is mostly intergranular. One reason for this behavior is the weakening of grain-boundary areas (where eutectic phases are located) as the alloy approaches the melting point. $\mathrm{T}_{\text {switch }}$ resembles equicohesive temperature [24,30], where above this temperature the matrix is stronger than the grain boundaries and it is reversed when the temperature is below. The ductility drop above $\mathrm{T}_{\text {switch }}$ may also due to the weak bond between the eutectic areas and the bulk aluminum grains, as has been previously reported for as-cast aluminum alloys in a similar temperature range [31]. Local pre-melting of eutectic phases at the grain boundaries [32] may further contribute to the observed change of the fracture mode. However, this is less likely as $\mathrm{T}_{\text {switch }}$ is approximately 15 ${ }^{\circ} \mathrm{C}$ below the nonequilibrium solidus point $\left(465^{\circ} \mathrm{C}\right)$ of AA7050. Figure 5 shows that hardening starts to saturate at $\mathrm{T}_{\text {switch. }}$. This is supported by the shape of stress and strain curves in Figure 1; above $T_{\text {switch }}$ there was hardly any hardening visible. This suggests an intrinsic change in the mechanical properties of the alloy in terms of response to tensile deformation at around $\mathrm{T}_{\text {switch. }}$.

SEM fracture surface analysis shows that at test temperature around the nonequilibrium solidus (i.e. at $465^{\circ} \mathrm{C}$ ), the morphology of eutectic phases seemingly depends on the strain rate. Eutectic phases in the samples tested at the lowest strain rate $\left(0.0005 \mathrm{~s}^{-1}\right.$, Figure $\left.7 \mathrm{~b}\right)$ exhibit filament-like morphology, which has been also observed by others upon low strain-rate tensile testing [33]. It was suggested that micro-superplasticity might be responsible. Cao et al. [34] considered three mechanisms operating during superplastic deformation; GBS, diffusion creep and dislocation creep, which correlates well with deformation mechanisms in our test regime. Previous works on micro-superplasticity proposed that filament formation is a result of viscous-flow of either semiliquid phase from incipient melt [33, 35, 36] or liquid-like substance [37]. A rather acceptable 
mechanism of filament formation proposed by Cao et al. [37] is as follows. The process starts by intensive GBS and eventually develops flow lines. Such flow lines extend over the grain surface in the tensile direction and ultimately become filaments during fracture process. However, there are other studies that suggest that filament formations are not related to incipient melting. For example, the filament formation may be due to chemical diffusion through grain boundary [36] and there is an observation of filament formation at a temperature well below the solidus, rendering incipient melting improbable $[38,39]$. Considering the test temperature $\left(465{ }^{\circ} \mathrm{C}\right.$ or approximately at nonequilibrium solidus), it seems appropriate to explain that filament formation in our case is a result of viscous flow of incipient melt. This is because at this temperature there might be a small fraction of eutectic that has started to melt, hence the possibility of viscous flow occurrence. Moreover, the eutectic intermetallics may become soft and liquid-like close to the eutectic melting point, thus enabling the suggested deformation mechanism. It is worth to note that diffusion is also highly active at this temperature. On the other hand, when the tests were done close to the solidus but at a higher strain rate of $0.05 \mathrm{~s}^{-1}$, the eutectic phases appear to be more rounded and no filament formation was observed. This suggests that the eutectic did not have sufficient time to elongate and compensate for the deformation. This observation is in accordance with the previous works on superplastically deformed materials showing that the length of filaments decreases as the strain rate increases [33, 37]. As our experiment was carried out at atmospheric condition, oxidation may also play significant role in stabilizing the filament formation, i.e. generating thin oxide layer around the filament as it formed [33].

The low-strength and low-ductility regime between $\mathrm{T}_{\text {solidus }}$ and $\mathrm{T}_{\text {switch }}$ may become a preferential regime for sub-critical propagation (growth) of solidification defects such as microscopic hot tears or pores. In particular, when such defects are exposed to thermal stress fields formed under a constrained cooling condition [40] or in a rapidly-cooled ingot after casting [3, 17]. Such exposure allows the defects to grow and coalesce and thus, generates larger defects. This suggests that a wider temperature range between $T_{\text {solidus }}$ and $T_{\text {switch }}$ increases crack growth susceptibility, which is an important point to consider during industrial production. It is well known that pores and micro-cracks have strong effect on mechanical properties of materials, in particular toughness and fatigue properties [41-45]. This ultimately may influence the service lifetime and the safety factor of the product. 


\subsection{Constitutive parameters of the alloy}

The small scatter in SSFS values (Figure 3) demonstrates good repeatability of the tests. This provided us with a good confidence of the source data for the constitutive parameter extraction. We obtained the constitutive parameters using the extended Ludwik equation (eq. 1) up to 450 ${ }^{\circ} \mathrm{C}$. Although there is still measurable hardening in this temperature regime, Figure 5 shows that hardening saturates above $440^{\circ} \mathrm{C}$ to a relatively small value. This is supported by Figure 1 . The reason we do not continue to fit the data to the extended Ludwik equation above $450{ }^{\circ} \mathrm{C}$ is because the hardening stage becomes very short. Thus the number of data points to be fit is below the limit of the measurement resolution. This produces very low but non-zero values that may not represent the actual physics of the material at such temperature regime.

Table 3 Comparison of the activation energy $(Q)$ and strain-rate sensitivity $(n)$ as the creep law constitutive parameters for AA7050 with reference data on other alloys.

\begin{tabular}{ccccccc}
\hline & $\begin{array}{c}\text { AA7050 } \\
\text { AC* }\end{array}$ & $\begin{array}{c}\text { Al-Cu } \\
\text { AC* } \\
\end{array}$ & $\begin{array}{c}\text { AA5182 } \\
\text { AC }[21,47]\end{array}$ & $\begin{array}{c}\text { AA5182 } \\
\text { HG** }[16]\end{array}$ & $\begin{array}{c}\text { AA1050 } \\
\text { HG** } \\
{[21]}\end{array}$ & $\begin{array}{c}\text { AA3004 } \\
\text { HG** }[21]\end{array}$ \\
\hline$Q(\mathrm{~kJ} / \mathrm{mol})$ & 185 & 154 & 125 & 174 & 157 & 194 \\
$n$ & 4.39 & 3.8 & 3.44 & 1.35 & 3.84 & 3.6 \\
\hline \multicolumn{7}{c}{ *AC $=$ as-cast; ${ }^{* *} \mathrm{HG}=$ homogenized } \\
\end{tabular}

From the creep-law parameters shown in Table 3, the as-cast AA7050 alloy exhibits relatively high values for both the activation energy $(Q)$ and the stress exponent $(n)$ in comparison with other aluminum alloys. However, the $Q$ value of our alloy $(185 \mathrm{~kJ} / \mathrm{mol})$ is within the range of other AA7XXX-series alloys. For example, an extruded AA7075 produces value around 131 $\mathrm{kJ} / \mathrm{mol}$ [5], another work reports that aged AA7075 and AA7150 have values between 155 and $162 \mathrm{~kJ} / \mathrm{mol}$ [48] and a solution treated AA7012 shows 200-230 kJ/mol [49], while an as-cast AA7020 is reported to have $173.8 \mathrm{~kJ} / \mathrm{mol}$ [50]. When compared to other AA7050 alloys processed through different routes, our alloy has a lower $Q$ as compared to the as-rolled AA7050 that produces $256 \mathrm{~kJ} / \mathrm{mol}$ [13]. Meanwhile, our alloy has a higher $Q$ as compared to the homogenized AA7050, which have values between 160 and $170 \mathrm{~kJ} / \mathrm{mol}$ for different homogenization routes $[11,12]$. As for the stress exponent $(n)$, when compared to other $7 \mathrm{XXX}$ alloys, an AA7075 alloy has a stress exponent of 6.7 [5], while an as-cast AA7020 alloy - 5.63 
[50]. These results show that AA7XXX-series alloys demonstrate relatively higher stress exponents than other series of aluminum alloys. At the same time, it seems that the values of both $Q$ and $n$ are sensitive not only to the alloying system and the amounts of alloying elements but also to the different processing route histories $[11,16]$. This is because different processing route histories (for instances, through rolling [51] or heat treatment [52]) can produce different microstructures. This eventually affects the deformation behavior, and ultimately the constitutive parameters of the alloy [52, 53].

\section{Conclusion}

In the present work, we studied the tensile mechanical properties, fracture behavior and extracted constitutive parameters of an as-cast AA7050 in the near-solidus temperature range (between 400 and $465^{\circ} \mathrm{C}$ ) at strain rates between 0.0005 and $0.05 \mathrm{~s}^{-1}$. We can conclude that:

1. Steady-state flow stress (SSFS) decreases with decreasing strain rate and increasing temperature. The strain-rate sensitivity of the alloy in this test regime is positive. From the ratio $(\delta)$ of SSFS value to shear modulus of AA7050 [22] that is between $3.5 \times 10^{-4}$ (at $465^{\circ} \mathrm{C}$ and strain rate of $0.0005 \mathrm{~s}^{-1}$ ) and $2.1 \times 10^{-3}$ (at $400^{\circ} \mathrm{C}$ and strain rate of $0.05 \mathrm{~s}^{-1}$ ), we suggest that GBS and dislocation creep is the dominant deformation mechanisms in this test regime.

2. Ductility of the alloy in this temperature regime decreases as the temperature and the strain rate increase. The alloy may become weaker as it approaches solidus through the coalescence of the formed voids. We observed a change in the temperature-ductility slope at approximately $450^{\circ} \mathrm{C}\left(\mathrm{T}_{\text {switch }}\right.$ ), which reveals the different preferential modes of failure below and above this temperature. Below $\mathrm{T}_{\text {switch }}$, the alloy fails mostly in the ductile transgranular mode, while above $\mathrm{T}_{\text {switch }}$ mostly in intergranular mode. The occurrence of $\mathrm{T}_{\text {switch }}$ resembles the equicohesive temperature; the grain boundary becomes weaker than the matrix above this temperature, while it is reversed below.

3. Micro-superplasticity phenomenon, i.e. formation of filament-like features on the fracture surface, is observed upon tests carried out at $465{ }^{\circ} \mathrm{C}$ and strain-rate of $0.0005 \mathrm{~s}^{-1}$. This feature is not observed at the same test temperature but at $0.05 \mathrm{~s}^{-1}$. Taking the test condition into account, the main formation mechanism of the filaments seems to be viscous flow of 
incipient melt or liquid-like substance. As this experiment was carried out in atmospheric condition, oxidation appeared to help in stabilizing the formation of the filaments.

4. The constitutive parameters in this temperature regime are obtained by fitting the experimental data to both the extended Ludwik equation and the creep law. For the extendedLudwik equation fit, we extracted the parameters in the temperature range where hardening is still significant; from 400 to $450{ }^{\circ} \mathrm{C}$. The obtained values are continuous with the results from an as-cast AA7050 alloy tested earlier in the lower temperature regime (between room temperature and $400^{\circ} \mathrm{C}$ ) [15]. We fit the data from the entire near-solidus temperature range to the creep-law equation because steady-state flow stress seems to be the dominant behavior in this temperature regime. The attained constitutive parameters ( $Q$ and $n$ ) are comparable with other $7 \mathrm{XXX}$-series alloys.

\section{Acknowledgement}

This research was carried out within the Materials innovation institute (www.m2i.nl) research framework, project number M42.5.09340. The authors would like to express their gratitude to Dr. D. Ruvalcaba and Mr. J. van Oord (Tata Steel Nederland Technology B.V.), and also Dr.ing. R. Sauermann (Aleris Europe) for their support and input. In addition, the authors also would like to thank Mr. J. M. Hofman (3mE faculty, Delft University of Technology) for his support during mechanical tests using Gleeble- $3800^{\mathrm{TM}}$ system. Support from Modelling assisted INnovation for Aluminum DC Casting process (MINAC) community is greatly appreciated.

\section{References}

[1] Y. Deng, Z. Yin, F. Cong, Intermetallic phase evolution of 7050 aluminum alloy during homogenization, Intermet, 26 (2012) 114-121.

[2] K.S. Al-Rubaie, M.A. Del Grande, D.N. Travessa, K.R. Cardoso, Effect of pre-strain on the fatigue life of 7050-T7451 aluminium alloy, Materials Science and Engineering A, 464 (2007) 141-150. 
[3] M. Lalpoor, D.G. Eskin, L. Katgerman, Cold cracking development in AA7050 direct chillcast billets under various casting conditions, Metallurgical and Materials Transactions A, 41A (2010) 2425-2434.

[4] T. Subroto, A. Miroux, D. Mortensen, M. M'Hamdi, D.G. Eskin, L. Katgerman, Semiquantitative predictions of hot tearing and cold cracking in aluminum DC casting using numerical process simulator, IOP Conference Series: Materials Science and Engineering, 33 (2012) 012068.

[5] A. Jenab, A. Karimi Taheri, Evaluation of low strain rate constitutive equation of 7075 aluminium alloy at high temperature, Materials Science and Technology, 27 (2011) 1067-1072.

[6] Y.C. Lin, G. Liu, A new mathematical model for predicting flow stress of typical highstrength alloy steel at elevated high temperature, Comput Mater Sci, 48 (2010) 54-58.

[7] M.R. Rokni, A. Zarei-Hanzaki, C.A. Widener, P. Changizian, The Strain-Compensated Constitutive Equation for High Temperature Flow Behavior of an Al-Zn-Mg-Cu Alloy, Journal of Materials Engineering and Performance, 23 (2014) 4002-4009.

[8] M. Lalpoor, Eskin, D. G., and Katgerman, L., Fracture behavior and mechanical properties of high strength aluminum alloys in the as-cast condition, Materials Science and Engineering A, 497 (2008) 186-194.

[9] L.J. Colley, M.A. Wells, D.M. Maijer, Tensile properties of as-cast aluminum alloy AA5182 close to the solidus temperature, Materials Science and Engineering A, 386 (2004) 140-148.

[10] T.A.S. Subroto, A.G. Miroux, D.G. Eskin, L. Katgerman, Constitutive behaviour of an ascast AA7050 alloy in the sub-solidus temperature range, IOP Conference Series: Materials Science and Engineering, 27 (2011) 012074.

[11] Y. Deng, Z. Yin, J. Huang, Hot deformation behavior and microstructural evolution of homogenized 7050 aluminum alloy during compression at elevated temperature, Materials Science and Engineering A, 528 (2011) 1780-1786.

[12] S. Liu, J. You, X. Zhang, Y. Deng, Y. Yuan, Influence of cooling rate after homogenization on the flow behavior of aluminum alloy 7050 under hot compression, Materials Science and Engineering A, 527 (2010) 1200-1205.

[13] H.E. Hu, L. Zhen, L. Yang, W.Z. Shao, B.Y. Zhang, Deformation behavior and microstructure evolution of 7050 aluminum alloy during high temperature deformation, Materials Science and Engineering A, 488 (2008) 64-71. 
[14] J.S. Jin, X.Y. Wang, H.E. Hu, J.C. Xia, High-temperature deformation behavior and processing map of 7050 aluminum alloy, Metals and Materials International, 18 (2012) 69-75.

[15] M. Lalpoor, D.G. Eskin, L. Katgerman, 12th International Conference on Fracture (ICF12), Ottawa, ON, Canada, 2009, pp. 407-415.

[16] W.M. Van Haaften, Materials Science and Engineering, Delft University of Technology, Delft, 2002.

[17] M. Lalpoor, Eskin, D. G., and Katgerman, L., Cold-cracking assessment in AA7050 billets during direct-chill casting by thermomechanical simulation of residual thermal stresses and application of fracture mechanics, Metallurgical and Materials Transactions A, 40A (2009) 3304-3313.

[18] H.G. Fjær, A. Mo, ALSPEN-A mathematical model for thermal stresses in direct chill casting of aluminum billets, MTB Metallurgical Transactions B, 21 (1990) 1049-1061.

[19] M. M'Hamdi, Mo, A., and Fjaer, H. G., TearSim: A Two-Phase Model Addressing Hot Tearing Formation during Aluminum Direct Chill Casting, Metall. Mater. Trans. A, 37A (2006) 3069-3083.

[20] A. Alankar, M.A. Wells, Constitutive behavior of as-cast aluminum alloys AA3104, AA5182 and AA6111 at below solidus temperatures, Materials Science and Engineering A, 527 (2010) 7812-7820.

[21] W.M. Van Haaften, B. Magnin, W.H. Kool, L. Katgerman, Constitutive behavior of as-cast AA1050, AA3104, and AA5182, Metallurgical and Materials Transactions A, 33 (2002) 19711980.

[22] H.C. Asm International, ASM handbook, ASM International, Materials Park, OH, 1990.

[23] H. Riedel, Fracture at high temperatures, Springer, Berlin, 1987.

[24] G.E. Dieter, Mechanical metallurgy, McGraw-Hill, New York, 1976.

[25] W. Ozgowicz, The relationship between hot ductility and intergranular fracture in a CuSn6P alloy at elevated temperatures, Journal of Materials Processing Technology, 162-163 (2005) 392401.

[26] M. Taheri-Mandarjani, A. Zarei-Hanzaki, H.R. Abedi, Hot ductility behavior of an extruded 7075 aluminum alloy, Materials Science and Engineering: A, 637 (2015) 107-122. 
[27] A. Haft Baradaran, A. Zarei-Hanzaki, H.R. Abedi, S.M. Fatemi-Varzaneh, A. Imandoust, The ductility behavior of a high-Mn twinning induced plasticity steel during cold-to-hot deformation, Materials Science and Engineering A, 561 (2013) 411-418.

[28] R. Raj, M.F. Ashby, Intergranular fracture at elevated temperature, Acta Metallurgica, 23 (1975) 653-666.

[29] H.J. McQueen, Hot deformation and processing of aluminum alloys, CRC, Boca Raton, Fla, 2011.

[30] W.D. Fei, H.Y. Yue, L.D. Wang, Equicohesive temperature of the interface and matrix and its effect on the tensile plasticity of Al18B4O33 whiskers reinforced aluminum composite at elevated temperatures, Mater Chem Phys, 119 (2010) 515-518.

[31] K.B.S. Couto, S.R. Claves, W.H. Van Geertruyden, W.Z. Misiolek, M. Goncalves, Effects of homogenisation treatment on microstructure and hot ductility of aluminium alloy 6063, Mater. Sci. Technol., 21 (2005) 263-268.

[32] K. Chattopadhyay, R. Goswami, Melting and superheating of metals and alloys, Progress in Materials Science, 42 (1997) 287-300.

[33] E. Giraud, M. Suery, M. Coret, Mechanical behavior of AA6061 aluminum in the semisolid state obtained by partial melting and partial solidification, Metall. Mater. Trans. A, 41A (2010) 2257-2268.

[34] W.D. Cao, X.P. Lu, A.F. Sprecher, H. Conrad, Superplastic deformation behavior of 7475 aluminum alloy in an electric field, Materials Science and Engineering: A, 129 (1990) 157-166.

[35] J.J. Blandin, B. Hong, A. Varloteaux, M. Suery, G. L'Esperance, Effect of the nature of grain boundary regions on cavitation of a superplastically deformed aluminium alloy, Acta Materialia, 44 (1996) 2317-2326.

[36] Y. Takayama, T. Tozawa, H. Kato, Superplasticity and thickness of liquid phase in the vicinity of solidus temperature in a 7475 aluminum alloy, Acta Materialia, 47 (1999) 1263-1270.

[37] W.D. Cao, X.P. Lu, H. Conrad, Whisker formation and the mechanism of superplastic deformation, Acta Materialia, 44 (1996) 697-706.

[38] W.J.D. Shaw, Microsuperplastic behavior, Mater Lett, 4 (1985) 1-4.

[39] M.G. Zelin, On micro-superplasticity, Acta Materialia, 45 (1997) 3533-3542.

[40] M.I. Onsoien, M. M'hamdi, O.M. Akselsen, Residual stresses in weld thermal cycle simulated specimens of X70 pipeline steel., Welding Journal, 89 (2010) 127-s - 132-s. 
[41] E. Charkaluk, A. Constantinescu, F. Szmytka, S. Tabibian, Probability density functions: From porosities to fatigue lifetime, Int J Fatigue, 63 (2014) 127-136.

[42] S. Mohd, Y. Mutoh, Y. Otsuka, Y. Miyashita, T. Koike, T. Suzuki, Scatter analysis of fatigue life and pore size data of die-cast AM60B magnesium alloy, Eng. Fail. Anal., 22 (2012) 64-72.

[43] J.Z. Yi, P.D. Lee, T.C. Lindley, T. Fukui, Statistical modeling of microstructure and defect population effects on the fatigue performance of cast A356-T6 automotive components, Materials Science and Engineering: A, 432 (2006) 59-68.

[44] M. Tiryakioğlu, On the size distribution of fracture-initiating defects in Al- and Mg-alloy castings, Materials Science and Engineering: A, 476 (2008) 174-177.

[45] M. Tiryakioğlu, On the relationship between statistical distributions of defect size and fatigue life in 7050-T7451 thick plate and A356-T6 castings, Materials Science and Engineering: A, 520 (2009) 114-120.

[46] O. Ludwig, J.M. Drezet, C.L. Martin, M. Suéry, Rheological behavior of Al-Cu alloys during solidification: Constitutive modeling, experimental identification, and numerical study, Metallurgical and Materials Transactions A, 36 (2005) 1525-1535.

[47] O. Ludwig, J.M. Drezet, P. Ménésès, C.L. Martin, M. Suéry, Rheological behavior of a commercial AA5182 aluminum alloy during solidification, Materials Science and Engineering A, 413-414 (2005) 174-179.

[48] T. Sheppard, A. Jackson, Constitutive equations for use in prediction of flow stress during extrusion of aluminium alloys, Materials Science and Technology, 13 (1997) 203-209.

[49] E. Cerri, E. Evangelista, A. Forcellese, H.J. McQueen, Comparative hot workability of 7012 and 7075 alloys after different pretreatments, Materials Science and Engineering A, 197 (1995) 181-198.

[50] Q.J. Liu, G. Fang, Analysis of constitutive behaviours and processing map of 7020 aluminium alloy, Materials Science and Technology, 26 (2010) 1088-1094.

[51] Q. Zeng, X. Wen, T. Zhai, Texture evolution rate in continuous cast AA5052 aluminum alloy during single pass hot rolling, Materials Science and Engineering A, 476 (2008) 290-300.

[52] J. Zhang, B. Chen, Z. Baoxiang, Effect of initial microstructure on the hot compression deformation behavior of a 2219 aluminum alloy, Mater. Des., 34 (2012) 15-21. 
[53] J. Luo, L. Li, M.Q. Li, Deformation behavior of Ti-5Al-2Sn-2Zr-4Mo-4Cr alloy with two initial microstructures during hot working, Trans Nonferrous Met Soc China, 26 (2016) 414-422. 